This is the peer reviewed version of the following article: Cleland, J. and Durning, S. J. (2018), Education and service: how theories can help in understanding tensions. Med Educ., which has been published in final form at https://doi.org/10.1111/medu.13738. This article may be used for non-commercial purposes in accordance with Wiley Terms and Conditions for Use of Self-Archived Versions.

\title{
Education and service: how theories can help in understanding tensions Jennifer Cleland ${ }^{1}$ and Steven J Durning ${ }^{2}$
}

${ }^{1}$ Centre for Healthcare Education Research and Innovation (CHERI), School of Medicine, Dentistry and Nutrition, University of Aberdeen, Aberdeen, UK

${ }^{2}$ Department of Medicine, Uniformed Services University of the Health Sciences, Bethesda, Maryland, USA.

\section{Corresponding author:}

Professor Jennifer Cleland

John Simpson Chair of Medical Education

Centre for Healthcare Education Research and Innovation (CHERI)

School of Medicine and Dentistry

University of Aberdeen

Foresterhill

Aberdeen

AB25 2ZD

Tel: 01224437257

Email: jen.cleland@abdn.ac.uk 


\section{Abstract}

\section{Objectives}

This paper reviews why tensions between service and education persist, and highlight that this is an area of medical education research (MER) which, to date, lacks a robust body of theory-driven research. After carrying out a review of the literature on service-training tensions in medical education and training, we turn to consider how theory can help provide new insights into serviceeducation tensions.

\section{Methods}

We conducted a search of the literature on service-training tensions since 1998 to examine the use of theory in studies on this topic.

\section{Results}

We identified $44 / 603$ relevant papers. Their focus fell into four broad categories: time residents spent on "service" and "education"; perceptions of the balance between service and education; considerations of how best to define service and education; and the impact of structural/systems changes on training. Of the papers reporting primary research the dominant methodology was the bespoke survey. Rarely were the precise natures of tensions or how different factors interact to cause tensions examined in detail.

\section{Discussion}

Through discussion and reflection, we then agreed on the applicability of four sociocultural theories for illuminating some examples of service-education tensions. We present four socio-cultural theories: Holland's figured worlds, Kemmis et al.'s practice architectures, Lave and Wenger's situated learning and Engstrom's cultural historical activity theory (CHAT or AT). We describe each and then briefly illustrate how each theory can support new ways of thinking and potential directions for research focusing on education-service tensions.

\section{Conclusions}

The use of theory in research studies will not resolve service-education tensions. However, what theory can do illuminate and magnify different aspects of service-education tensions, to generate new insight and knowledge that can then be used to inform future research and changes in practice. 


\section{Introduction}

The main purpose of healthcare environments is to provide safe and effective health care. However, at the same time as delivering high quality patient care, hospitals, clinics and other healthcare facilities also host the education and training of future generations of health professionals (1). This results in the situation where service and education compete for limited time and resources (2). Medical education is one of multiple, competing demands for Consultants and other healthcare faculty working in increasingly pressured and regulated environments $(3,4)(5)(6)$. Doctors-in-training (residents or registrars) also face increasing educational pressures due to, for example, the need to achieve competencies within fewer hours (7-9) and the expansion of medical and technological knowledge (10).

In short, increased practice and educational demands in the milieu of growing regulatory restrictions mean less time is available for faculty to teach and for trainees to learn in today's healthcare environment. This challenge is reflected in health care settings globally (e.g., $(11,12))$. It appears to be contributing to resident/trainee dissatisfaction and an increasing pattern of residents/trainees wishing to either take time out of training, quit training or move into medical jobs without patient contact (13-18).

Responses to the challenge of tension between education and service have been diverse. These have included calls for the transformation of medical education, such as shifting from traditional ward teams to more education-oriented services $(19,20)$ and/or alternative pedagogic methods such as simulation-based education (21-23). These different approaches are undoubtedly worthwhile. However, if the majority of medical training continues to be delivered in healthcare contexts where trainees/residents meaningfully participate in the delivery of patient care (and we cannot imagine a 
scenario where this would not be the case), then it is essential to examine how service and education can be aligned productively rather than seen as separate, competing activities (24-26).

This paper proposes that one of the reasons why tensions between service and education persist is because this is an area of medical education research (MER) which, to date, lacks a robust body of theory-driven research. After providing a brief overview of the literature on this topic, we discuss how theory can help provide new insights into service-education tensions by examining the application of four specific theories to this problem.

\section{Methods}

We carried out a review of the literature on service-training tensions in medical education and training. The purpose of our search was not to assess published research on this topic for rigour, or to compare study outcomes using a formal methodology for doing so. Rather, we were interested in study focus and use of theory/robust methodologies.

We searched Scopus and PubMed databases in that order. Note that Scopus includes Embase and Medline. We used the search terms "service", "training", "medicine", "residents", "balance", "tensions" and "patient care" individually and in combination (e.g., "service" and "training" and "tensions"). We search for English-language papers from 01 January 1998 to 15 May 2018 which focused on medical not healthcare education and training, trainees not medical students. This time span of just over 20 years was pragmatic rather than linked to any index events given these are typically context-specific (e.g., national-level changes in training such as the UK's Modernising Medical Careers (27). The search initially identified 603 papers, narrowed down to 44 after checking abstracts and full papers for relevance, and removing duplicates. 
The focus of the identified papers fell into four broad categories. These were: studies describing the proportion of time residents spent on "service" and "education" when in the workplace (for example (28); residents' (and/or trainers') perceptions of the balance between service and education in their activities (for example (29)); considerations of how best to define service and education (for example (24-26)); and studies identifying the impact of structural/systems changes (at a national or local level) on training and/or patient care (for example, $(30,31)$. Of the papers reporting primary research (as opposed to reviews, or discussion articles), the dominant methodology was the bespoke survey $(24,32,33)$, followed by descriptive qualitative inquiry $(2,13)$.

What was clear from the literature is that medical educators and doctors in training/residents hold mismatched impressions of their training programs' balance of service obligations with clinical education. Specifically, residents more frequently report an overabundance of service. Both groups acknowledge that service activities can be educationally valuable although the residents' and trainers' definitions of service and training are not fully aligned.

These tensions make sense in terms of the wider literature on workplace learning. For many authors there is no separation between participation in work and learning (34). Work activities, the workplace, other workers and observing and listening are consistently reported as key sources for workers to learn their vocational activities through work (35). What does differ, however, is the value individuals place on different activities within the workplace. What is valued is associated with personal and vocational goals and is a product of knowledge, ways of thinking, occupational "standing" and life history as well as more "in-the-moment" experiences of what the workplace affords (36-38). Moreover, learners are more likely to recognise and privilege formal learning opportunities, and be more motivated to be receptive to these, compared to the more assimilative and accommodative learning that takes place in the workplace $(38,39)$. Given this, it is unsurprising 
that consultants/trainers and trainees/residents have different perspectives on the same activities, and different definitions of what is service and what is training.

However, our literature search indicated that only infrequently have attempts been made to clarify the precise nature of these different perspectives, or tensions (for exceptions see $(40,41)$, or how different factors may interact to cause such tensions in medical education (42). Instead, typically studies have lacked a theoretical or conceptual underpinning (43). These are major criticisms of work on this topic, which, like several others in medical education, "lags behind" areas where theories and methodologies have been borrowed from other fields and have been incorporated with the goal of advancing our understanding and practice.

\section{The use of theoretical frameworks}

Theory can provide a framework to organise and interpret the data in such a way as to highlight commonalities and patterns and generate conceptual generalisability $(44,45)$. The advantages of this are multiple. First, findings can be assessed by others for their transferability and potential for applicability to other situations and different contexts (46). Second, the use of theoretical framing helps develop robust explanations of the phenomena under study, which can be elaborated and refined in future research (47). Third, theory can provide a roadmap of expected associations and/or interactions from one field that can be used to understand a previously underexplored phenomenon. Finally, conceptual and/or theoretical frameworks are a means to illuminate and magnify certain aspects of the problem under study (48). Indeed, more than one conceptual and/or theoretical framework may be relevant to a given situation, particularly situations which involve complex social issues $(48,49)$. 
We suggest that examining education-service tensions through diverse theoretical lenses can illuminate these tensions and allow researchers to contribute meaningfully to medical education research and scholarship on this topic. To support this proposal, in this paper we apply four examples of theoretical frameworks to identify common underlying issues and potential solutions to education-service tensions. These are: figured worlds $(50)$, practice architectures $(51,52)$, situated learning (53-55), and cultural-historical activity theory (CHAT or AT: (56-58)). One of these - practice architectures - is to the best of our knowledge, quite novel to MER. The others have been used in MER but not to the very specific topic of addressing service-training tensions.

But why these theories? Our stance is that learning is social and participatory (59) and thus situated in social contexts so we have drawn our theories primarily from the broad family of sociocultural theories. From this perspective, service and education occur in the social context of the workplace and are shaped by, and in turn shape, the other people and interactions in the workplace context. Learning involves not only acquiring particular knowledge and skills (e.g., the causes of breathlessness, how to put in an endoscope) but also engagement with a particular professional community of the other people in the workplace ((53-55) see later for further discussion). Some theories take more account of the role of artifacts ("things") as well as other people in learning contexts, practices, and identity formation than others. Practice architecture theory $(51,60)$ and CHAT (56-58) are situated within the broadly socio-material arena, where "environment, other animals, objects and artefacts are treated as integral to the enactment of human existence and social life rather than as simply background context or tools" (61) (p49). Those of a socio-material persuasion may accept learning as participation not acquisition, but they also seek granularity in their analyses of participation: who and what participate, and how, with what effects? (62). Human agency is only one part of the jigsaw -non-human materials (e.g., "the rota", the resident's portfolio, the communication system) also have power and impact in this school of thought. Moreover, different people relate themselves to their social (workplace) surroundings in various ways. Actors' 
(individuals') positions may shift over time, and there may be gaps between an actor's perception of activities and the professional practice and identity with which they are associated with their position in the social and cultural world, due to their own "historical-cultural baggage" (e.g., their gender, ethnicity, past experiences, expectations and so on) (63) (p.283) (50).

Our four examples of theory view interactions, participants and the component parts of complex social settings in unique ways that can be leveraged to explore service-education tensions. We describe each and then briefly illustrate how each theory can support new ways of thinking and potential directions for research focusing on education-service tensions. We have made suggestions as to how each theory could be helpful in changing educational-service models for the better. The four theories, what they emphasize, their utility and some examples of possible research questions on the topic of service-education tensions which could be addressed by each theory are presented in Table 1. Note that some of the example research questions chosen could be addressed through more than one theory in the table, an approach which, if pursued, could lead to even greater understanding of the service-training tensions (49).

\section{Table 1 about here}

\section{Figured worlds}

Holland et al. (1998 (50)) broadly defined figured worlds as "socially produced, culturally constituted activities" (pp. 40-41) where people produce (perform) new self-understandings (identities). Figured worlds are culturally and socially based, mediated by relations of power, status, and rank, implicated and organised through daily activities. Each figured world is organized by socially-constructed preconceptions on which the world is based (such as: as a doctor-in-training I am here to be taught). Day-to-day social practices and activities are interpreted against these narratives (e.g., one activity is 
seen as a service "job", another is seen as an educational opportunity). Trainees must negotiate the multiple identities of learner and a doctor who delivers service within the same space, leading to tensions arising from systems and identities in constant flux (64).

Figured worlds are not static, rather they are constructed and reconstructed through daily actions and a process of "positionality"; that is, the positions "offered" to people in a certain figured world (such as trainee, or Consultant/Supervisor) which they may accept, reject, or negotiate. This is called the "space of authoring" (50). Where there is a challenge, when for example the figured world is different to what was originally constructed, an individual's response may be to re-write themselves into (or out of) that particular world. These personal negotiations - referred to as improvisations take place against the macro figured world of medical education (65).

Figured world theory has been applied extensively in education (65-68) and more recently in medical education, specifically in the area of identity development in medical students $(69,70)$, female surgeons (71) and medical educators (72). Bennett et al. (73) provide an overview of the central tenets of Figured world theory.

\section{Applying the theory of figured worlds to service-training tensions}

Conceiving of medical training as a culturally figured world reveals how policies about service and training work to shape practices, and how dominant narratives (e.g., service is prioritised over training) may work to shape the practices of, and identities available to, trainees/residents (and their trainers). This is not about cause and effect but about the figured world of trainees/residents emerging and shifting over time, and what it is that contributes to shifts. For example, where trainee/residents' expectations about how their education needs to be supported are unmet $(25,42,74)$ they may think of quitting training or shifting to another specialty. Are these responses due to the world of medical training not being what they expected, even after many years of 
observation from the lesser-powered position of student (75)? Is it because the (often unspoken) expectations they have of their educators are not being meet (76)? And/or what is the coconstruction between the individual, shaped by their history and past experiences (e.g., their previous employment and learning experiences), and their interaction with the world of medical training? If they experience contexts where service and training are not well balanced, where they do not feel they are adequately supported in their professional development, are they less likely to apply for higher-level training? This pattern is seen in other educational contexts: Boaler and Greeno (77) found that different settings afforded mathematics (maths) students different opportunities, and these different opportunities made a significant impact on their choices about continuing or dropping out.

Although the current dominant narrative is that service is prioritised over training (see earlier), figured worlds theory may also provide a way of promoting resistance to this discourse, a means of refiguring the identity of learning/learners within medicine. This refiguring is likely to occur in relation to ruptures, changes and/or opportunities which open up critical comment, impact on the discourse of what is valued, create new figured worlds and imagined futures (50).

\section{Practice architectures}

Kemmis and Grootenboer $(60)$ and Schatzki $(78,79)$ propose that education practices are held in place by preconditions - practice architectures - that shape, enable and constrain some kinds of action at the expense of others. Broadly speaking, the theory of practice architectures focuses on place rather than the individual (as is the case in figured worlds theory).

This theory is inherently social and cultural, emphasising that practices occur in, and are enmeshed with, places. For example, the organisation of medical training may very similar overall, but what 
precisely happens in practice in diverse sites - the practice landscapes - may differ. These practice architectures may relate to material and economic conditions (e.g. how healthcare organisations are paid for delivering training, how training is organised and managed, what happens if the team is short of a resident). They might be social and political relationships, such as the relationships within a team, between trainees and their supervisors, or between doctors and their employers. They may be cultural and discursive ("How things are done around here").

Kemmis et al. (51) suggest that practices in the social world hang together in 'three dimensions of intersubjectivity' (p. 23) formed in semantic space, in physical-space time and in social space. These intersubjective spaces form places for education to be enacted through "sayings", "doings" and "relatings". The notion that these 'hang together' in a practice is important because it means that practices cannot be reduced to any one of these actions on its own. These dimensions of subjectivity, and how they relate, are presented in Figure 1.

Figure 1 about here

From this theoretical perspective, changing practices requires not only changing the awareness, understanding, concerns and skills of individual participants, but also changing the practice architectures that hold existing practices in place.

\section{Applying practice architecture theory to service-training tensions}

The theory of practice architectures can help reveal the ways training and service are enabled and constrained by the conditions under which they occur, and how these conditions (the practice architectures), make them possible and hold them in place. It can also be a transformational resource for finding ways to change medical educational training (52): only by identifying and understanding what is maintaining the status quo can you attempt to change it. 
The first of these is descriptive: how are medical training practices constituted in individual actions the sayings, doings and relatings - and how these are linked. The second is more analytic, exploring how practice is enabled and/or constrained by the set-up of the world in which medical training is situated. For example, what resources are available (e.g., do the junior doctors have their own room or hot desk with the nurses; how are things funded; who owns on-line portfolio resources)? What are the arrangements like in terms of organisational rules, hierarchies, relationships within and beyond the organisation? At the individual (agency) level, what influences relationships (e.g., experience, clinical load, familiarity with the healthcare and education set-up, materials and expectations? How do these cultural-discursive, material-economic and social-political arrangements shape each other (80)?

The third use of the theory is to examine how practice architectures can be changed. Generally speaking, the practice architectures of medical education and training are well-embedded in tradition, and more recently in accountability pressures, work intensification, and standardisation of practices, which may limit ways in which individuals may be able to respond to disruptions and possibilities to change what they say and do, and how they relate (60). Yet we see plenty of differences between units embedded within the same system. For example, in one of our recent studies, a consultant had been suspended, but his/her "doings" and "relatings" had left residual traces in memories, activities and the relationships of those left in the setting (42). These residuals opened possibilities of practice, helping the next generation of training (residency) programme directors and consultants identify educational areas to target for change. These changes were restrained by systems factors (e.g., the timing of operative lists), but they engaged with this landscape to encourage change (e.g., bringing in protected learning time). 
The theory of practice architectures is useful as an analytic tool for exploring how various different dimensions of education and service are interconnected. Practice architecture theory allows us to view practices from a stance that considers how individuals and groups respond to circumstances and people, and how responses shape practice and change the education landscape. This theory could be used as a framework for considering the impact of change on learning and service delivery. For example, how does a change of residency programme director shape the local training arrangements? What is the impact of new training or working regulations on relationships and delivery of care? How does a unit respond to a crisis such as a trainee quitting? Analysing responses from in this way will provide useful, transferable messages for other units and departments.

\section{Situated Learning}

Situated learning is a view of learning first developed by Jean Lave and Etienne Wenger in the 1990s $(53,81,82)$. Situated learning emphasizes the importance of social interactions and active participation in learning. It goes further in stressing the necessity of actual experiences to creating meaning. Thus, Lave and Wenger view learning as an inherently social and interactive process based on lived experiences. Learning is therefore about becoming or forming one's identity as opposed to the acquisition of facts and/or symbols in memory.

There are two key component parts (which now are sometimes cited as two separate theories) to situated learning theory - communities of practice (COP) and legitimate peripheral participation (LPP). Learning takes place (i.e. is situated) as it takes place within a specific place and time and involves interacting within a specific community of practice (CoP). Learning within this community entails active participation (or practice) that expands over time. More experienced, or core, members of the CoP, are familiar with its practices, history and culture while newer members are more peripheral, advancing their learning through greater active participation in the CoP. Newer 
members move from peripheral to more full participation, or from being a beginner to a more expert member, through time and experience (83). In other words, participation in the authentic activities of the community (CoP) builds relationships and knowledge that lead to learning (through LPP) and in turn learning entails becoming a part of a community $(84,85)$.

A CoP is believed to emerge around mutual goals, objectives and interests of community members. Interestingly, recent research shows that artificially-created CoPs are problematic. Rather they need to evolve naturally to capture the power and potential of situated learning (86). LPP is also believed to emerge through a naturally-occurring, dynamic process within a CoP.

\section{Applying situated learning theory to service-training tensions}

Importantly, situated learning does not view tension (in this case tensions between service and training) as being good or bad and acknowledges that tensions (through negotiation) are actually a part of learning. The differing roles as one moves from peripheral to more full participation in the community lead to natural tensions (that can help learning). Thus, situated learning would acknowledge the tensions and their role and would seek to understand the sources of the tensions and how participation could be designed optimally, to enable the learner to become a more prominent part of the community. Through acknowledging the role of the tension for learning and seeking ways to optimize the tension for the learner (so that they can become full members of the CoP and providing full participation) the goal is not removing the service vs teaching tension but rather optimizing it.

Situated learning theory would also question the roles of service and teaching for the CoP in addition to seeking ways to optimize LPP though exploring these tensions. Further, situated learning would consider how other, related, CoPs may be impacted through this exploration (86). These theoretical tenets could be leveraged to help understand trust, progressive independence of the learner, 
dynamics of ward and clinical teams (e.g., what is the role of peers in increasing participation?), implicitly (and explicitly) held values, beliefs, and biases to name a few potential lines of work. This exploration would not only pertain to the service vs teaching tension but to other community member roles, and how the learning activities (LPP) are structured (and optimized).

Situated learning could provide a useful way to exploring how interns (or PRHOs) learn to become ward team residents (registrars). Likewise, this theory could be used to inform what legitimate participation means for a clinic, operating room, and/or ward.

\section{Cultural Historical Activity Theory (CHAT or AT)}

Cultural Historical Activity Theory (56-58) offers a way of understanding human action and learning that, like situated learning, takes into account not only the individual but also their social and cultural context. It does so in a different way. AT considers an entire activity (or work) system to include all of its component parts and how they interact. These component parts include individual subjects, objects of work, the community, division of labour for the community, community rules, and their interactions. Engestrom's original framework has expanded over the years to incorporate networks of multiple interacting activity systems, to acknowledge that different systems overlap (Third-generation AT (56): see Figure 2).

\section{Figure 2 about here}

AT can be summarised with the help of five principles. Unlike CoP and LLP, the system, not the individual, is the unit of analysis. For example, the overarching system could be that of medical training and other, (sub-) systems (such as surgical or family medicine training) would operate within this overarching system. The system is multi-voiced with different positions within the system for 
different participants (education would typically involve residents at different stages of training, supervisors/trainers/Faculty, and possibly other groups such as administrators). Both the participants and the system itself carry histories, rules and so on (this could refer to social structures and hierarchies such as the training programme or residency director being in overall charge locally). Systems are understood against their own history and context, and contradictions or structural tensions within and between activity systems are a source of change (expansive transformation) and development (or, less positively, can block change).

Where there are networks of different systems interacting (e.g., the numerous bodies and organisations involved in medical training in the UK), the multi-voicedness is multiplied. This is very relevant to studies of the tensions between education and healthcare. A healthcare system will "host" an education system, and within the overall education system will be smaller systems such as specific residency programmes, and host units within different facilities, which the same healthcare provider may manage, or which may be managed by diverse providers.

By being explicit about these components and how they interact within and between systems, AT can bridge the gap between the individual participant and the social reality, which is an element of the service-teaching tension. Thus, while arguably encompassing both CoP and LPP, and with similarities to practice architectures, AT details the individual component parts (to include objects), interactions and the larger system.

For example, in contexts where residency posts lie empty, there are immediate issues of service delivery, plus longer term issues of training sufficient numbers of doctors to Consultant grade for future service. To do will require working across systems boundaries, to tie otherwise separate systems of activity together (e.g., medical schools admissions, postgraduate training providers, employers, the regulator, and the groups which stands up for the rights of all junior doctors on 
education, training and contractual issues). AT can help make explicit the history and culture of each of these groups/systems, and examine how different activity systems interact with each other, to understand dialogues and multiple perspectives of interacting activity systems (87). The deeper understanding of influences and relationships enabled by using the AT framework can inform progress, and help units learn from their history.

\section{Applying AT to service-training tensions}

AT offers a unique approach for exploring the tensions between service and teaching. It clearly defines each of the component parts, how these parts interact and provides a lens for both anticipated and unanticipated findings. AT could be used to explore how motivation, community rules and division of labour may impact on the individual and the system. For example, activity theory could be applied to complex ward or clinic settings with multiple participant groups and varying rules and cultures to enhance our understanding of these tensions.

A strength of AT is that it provides a theoretical lens for understanding and analyzing the serviceeducation tensions, allowing for the identification of patterns and making inferences through interactions, describing the phenomena of the service-teaching tension and presenting this phenomena through a built-in language and rhetoric. AT has been successfully applied to the simulation literature, providing a unique lens to understanding a complex activity with multiple participants, rules, and tensions $(87,88)$. AT has also been used to inform complex inter-professional team debriefings, providing a way to potentially reframe observations and interactions in complex social settings, prioritize and identify additional topics for debriefing, and facilitate the identification of factors that promote or impede patient safety (89).

Like situated learning, AT brings the opportunity to investigate service-education tensions primarily though qualitative means although quantitative methods can also be used. Further, AT can be 
leveraged to explore sub-tensions (or the component parts leading to tensions) within or between teaching and service through the term "contradictions".

For example, AT could provide a useful lens to exploring the dynamics and tensions of hospital team sign outs to other teams. AT could provide a useful lens into how Electronic Health Records "work" in busy clinical settings.

\section{Conclusion}

There are many other potentially useful theories that we have not been able to discuss because of space constraints. For example, we have commented in previous papers that organisational psychology/management theories and principles are used rarely in medical education research yet these are eminently applicable given their focus on organizations (e.g., medical schools, hospitals, other healthcare settings) and individuals within these organisations (e.g., trainers, residents, wider team members). Indeed, one of the few papers in the medical education literature which used a management theory looked specifically at service-training tensions, providing new ways of thinking about the issue (42). The insights from this study also illuminated new areas worthy of more granular exploration, such as exploring how Consultants and trainees engage with, resist, accommodate, reproduce and transform managerial systems and mechanisms of control (such as rotas, operating time, and whether trainee/residents are assigned to particular operating lists, or not (see (90) for an overview of the study of resistance in organisational life)). Or rather than looking at organisational power using a management lens it could be looked at using a completely different group of theories, those of discourse $(91,92)$. Discourse theory could provide a lens by which to explore the language used by Consultants, residents and other stakeholders, language which maintains the (apparent) division between service and education. Are these actually different? One consequence of this divisive discourse sets up some activities as legitimate learning, others as "just 
jobs". Moreover, has the current division between service and education always been the case? Has the discourse changed over time and, if so, what forces have shaped it?

Our point is that there are many theories which have the potential to elucidate particular aspects of service-education tensions. Which you choose will be dependent on your particular research interest and question(s), and your own preferences. The four main theory choices we present in this paper are idiosyncratic, drawn from our personal and mutual research and education interests. That these preferences are influenced by our different backgrounds and training was obvious to us when preparing this article (SJD is a medical doctor and educationalist based in the USA, JC a clinical and occupational psychologist working in medical education and based in the UK). We view these differences as productive and one of the gains from working in a sub-discipline which draws together people from many different professional groups. However, someone working from a different personal epistemology may have focused more on, for example, the role of individual cognitive processes in learning in the workplace, including learner-related factors such as motivation, accurate metacognitive monitoring of learning, task complexity and cognitive load (93). This would be perfectly valid, and would add to the body of knowledge and understanding of workplace learning in a different way from the theories we suggest.

The theories we have suggested are typically coupled with qualitative research methods and data collection tools. Part of the reason for this is that sociocultural theories involve interactions with other participants and the environment which inherently means non-linearity and the emergence of the unforeseen (94). However, on the other hand, a different theoretical lens on workplace learning, such as the aforementioned cognitive theories, would require different study designs, methodologies and data collection tools (95). 
In conclusion, while acknowledging that our brief presentation of these theoretical approaches risks conveying a simplistic view of them, our aim in this paper was to illustrate two things. First, that "there is nothing as practical as a good theory" (96) in relation to examining the tensions between service and education. Our second point is that different theories will illuminate and magnify different aspects of a phenomenon, in this case of service-education tensions. We do not claim that the use of theory in studies will resolve service-education tensions. What theory can do is help us compare a variety of such tensions across different healthcare contexts and situations, find patterns in socially complex situations, and provide explanations that can then be used to inform future research and changes in practice which acknowledge that service delivery and learning are inexorably linked in medical training and practice.

5230 words 


\section{Acknowledgements}

Our thanks to Ayelet Kuper for a helpful discussion about the possible application of discourse analysis to service-training tensions.

\section{Funding}

None.

\section{Conflicts of interest}

None.

\section{Disclaimer}

The views expressed herein are those of the authors and not necessarily those of the Department of Defense or other federal agencies.

\section{Ethical approval}

Not applicable.

\section{Contributions}

Both authors developed the idea for this paper. JC prepared a preliminary draft of the paper which both authors revised for critical content. Both JC and SD approved the final version of the paper. 


\section{References}

(1) Peirce JC. The paradox of physicians and administrators in health care organizations. Health Care Manage Rev 2000;25(1):7-28.

(2) O'Keeffe C, Carter A, Mason S. The value of emergency medicine placements for postgraduate doctors: views of Foundation Year 2 doctors and training leads in the emergency department (ED). . Postgraduate Medical Journal 2017;93:15-19.

(3) Goodrick E, Reay T. Constellations of institutional logics: Changes in the professional work of pharmacists. Work Occup 2011;38(3):372-416.

(4) Reay T, Hinings CR. Managing the rivalry of competing institutional logics. Organ Stud 2009;30(6):629-652.

(5) OECD. Health statistics: Frequently requested data. Available at: www.oecd.org/els/healthsystems/oecd-health-statistics-2014-frequently-requested-data.htm. Accessed February 2018.

(6) Ferlie E, Ashburner L, Fitzgerald L, Pettigrew A. The new public management in action. New York: Oxford University Press; 1996.

(7) Greenaway D. Shape of Training: Securing the Future of Excellent Patient Care. 2013; Available at: https://www.shapeoftraining.co.uk/static/documents/content/Shape of training FINAL Report.pd f 53977887.pdf. Accessed March, 2018.

(8) Quinn A, Brunett P. Service versus education: Finding the right balance: A consensus statement from the council of emergency medicine residency directors 2009 academic assembly "Question 19" working group. Acad Emerg Med 2009;16(SUPPL. 2):S15-S18.

(9) General Medical Council (GMC). National Training Survey. 2016; Available at: https://www.gmcuk.org/education/surveys.asp. Accessed March, 2018.

(10) Densen P. Challenges and opportunities facing medical education. Trans Am Clin Climatol Assoc 2011;122:48-58.

(11) Rimmer A. Workloads threaten to undermine doctors' training, GMC finds. BMJ 2016;355:i6495.

(12) Henning MA, Shulruf B, Hawken SJ, Pinnock R. Changing the learning environment: The medical student voice. Clin Teach 2011;8(2):83-87.

(13) Spooner S, Pearson E, Gibson J, Checkland K. How do workplaces, working practices and colleagues affect UK doctors' career decisions? A qualitative study of junior doctors' career decision making in the UK. BMJ Open 2017;7(10).

(14) Spooner S, Gibson J, Rigby D, Sutton M, Pearson E, Checkland K. Stick or twist? Career decisionmaking during contractual uncertainty for NHS junior doctors. BMJ Open 2017;7(1).

(15) Rich A, Viney R, Needleman S, Griffin A, Woolf K. 'You can't be a person and a doctor': The worklife balance of doctors in training - A qualitative study. BMJ Open 2016;6(12). 
(16) Cleland JA, Johnston P, Watson V, Krucien N, Skåtun D. What do UK medical students value most in their careers? A discrete choice experiment. Med Educ 2017;51(8):839-851.

(17) Degen C, Weigl M, Glaser J, Li J, Angerer P. The impact of training and working conditions on junior doctors' intention to leave clinical practice. BMC Med Educ 2014;14(1).

(18) Ochsmann EB. Thinking about giving up clinical practice? A gender-stratified approach to understanding junior doctors' choices. Acad Med 2012;87(1):91-97.

(19) McMahon G, Katz JT, Thorndike ME, Levy BD, Loscalzo J. Evaluation of a redesign initiative in an internal-medicine residency. New Engl J Med 2010;362(14):1304-1311.

(20) O'Connor AB, Lang VJ, Bordley DR. Restructuring an inpatient resident service to improve outcomes for residents, students, and patients. Acad Med 2011;86(12):1500-1507.

(21) Boet S, Borges BCR, Naik VN, Siu LW, Riem N, Chandra D, et al. Complex procedural skills are retained for a minimum of $1 \mathrm{yr}$ after a single high-fidelity simulation training session. $\mathrm{Br} \mathrm{J}$ Anaesth 2011;107(4):533-539.

(22) Cook DA, Hatala R, Brydges R, Zendejas B, Szostek JH, Wang AT, et al. Technology-enhanced simulation for health professions education: A systematic review and meta-analysis. J Am Med Assoc 2011;306(9):978-988.

(23) Watson K, Wright A, Morris N, Mcmeeken J, Rivett D, Blackstock F, et al. Can simulation replace part of clinical time? Two parallel randomised controlled trials. Med Educ 2012;46(7):657-667.

(24) Kesselheim JC, Sun P, Woolf AD, London WB, Boyer D. Balancing education and service in graduate medical education: Data from pediatric trainees and program directors. Acad Med 2014;89(4):652-657.

(25) Sanfey H, Cofer J, Hiatt JR, Hyser M, Jakey C, Markwell S, et al. Service or education: In the eye of the beholder. Arch Surg 2011;146(12):1389-1395.

(26) Turner TL, Fielder E, Ward MA. Balancing service and education in residency training a logical fallacy. JAMA Pediatr 2016;170(2):101-102.

(27) Department of Health. Modernising medical careers. The next steps. 2004; Available at: http://webarchive.nationalarchives.gov.uk/20110929193948/http://www.dh.gov.uk/prod consum dh/groups/dh digitalassets/@dh/@en/documents/digitalasset/dh 4079532.pdf. Accessed March, 2018.

(28) Landmann A, Mahnken H, Antonoff MB, White S, Patel A, Scifres AM, et al. Keeping Residents in the Dark: Do Night-Float Rotations Provide a Valuable Educational Experience? J Surg Educ 2017;74(6):e67-e73.

(29) Nomura O, Mishina H, Jasti H, Sakai H, Ishiguro A. Pediatric resident perceptions of shift work in ward rotations. Pediatr Int 2017;59(10):1119-1122.

(30) Wagner MJ, Wolf S, Promes S, McGee D, Hobgood C, Doty C, et al. Duty hours in emergency medicine: Balancing patient safety, resident wellness, and the resident training experience: $\mathrm{A}$ 
consensus response to the 2008 institute of medicine resident duty hours recommendations. Acad Emerg Med 2010;17(9):1004-1011.

(31) Cohee BM, Hartzell JD, Shimeall WT. Achieving balance on the inpatient internal medicine wards: A performance improvement project to restructure resident work hours at a tertiary care center. Acad Med 2014;89(5):740-744.

(32) Kesselheim JC, Schwartz A, Boyer D, Barone S, Boland K, Dunbar A, et al. Integrating Education and Service in Pediatric Residency Training: Results of a National Survey. Acad Pediatr 2017;17(8):907-914.

(33) Reinke CE, Kelz RR, Pray L, Williams N, Bleier J, Murayama K, et al. Trimming the fat: Optimizing overall educational value by defining factors associated with overall educational value and serviceto-education ratio. J Surg Educ 2012;69(6):813-818.e1.

(34) Lave J. The practice of learning. In: Chaiklin S, Lave J, editors. Understanding practice:

Perspectives on activity and context. Cambridge, UK: Cambridge University Press; 1993. p. 3-32.

(35) Billet S:. Guided learning in the workplace. In: Boud D, Garrick J, editors. Understanding Learning at Work London: Routledge; 1999.

(36) Darrah C. Complicating the concept of skill requirements: Scenes from a workplace. In: Hull G, editor. Changing work, Changing workers: Critical perspectives on language, literacy and skills. New York: State University of New York Press; 1997. p. 249-272.

(37) Billett S. Personal epistemologies, work and learning. . Educational Research Review 2009;4:210-219.

(38) Illaris K:. The three dimensions of learning. Copenhagen/NIACE: Leicester: Roskilde University Press; 2002.

(39) Illeris K. Factors that influence informal learning in the workplace. Journal of Workplace Learning 2003;15(4):167-178.

(40) Ajjawi R, Rees C, Monrouxe L. Learning clinical skills during bedside teaching encounters in general

practice. A video-observational study with insights from activity theory. Journal of Workplace Learning 2015;27(4):298-314.

(41) Yardley S, Cottrell E, Rees E, Protheroe J. Modelling successful primary care for multimorbidity: a realist synthesis of successes and failures in concurrent learning and healthcare delivery. BMC Family Practice 2015;16(23):https://doi.org/10.1186/s12875-015-0234-9.

(42) Cleland J, Roberts R, Kitto S, Strand P, Johnston P. Using paradox theory to understand responses to tensions between service and training in general surgery. Med Educ 2018;52(3):288301.

(43) Cook DA, Bordage G, Schmidt HG. Description, justification and clarification: a framework for classifying the purposes of research in medical education. Med Educ 2008;42(2):128-133. 
(44) Stake RE. The art of case study research. The art of case study research. Thousand Oaks, CA: Sage; 1995.

(45) Gibbs T, Durning SJ, van der Vleuten C. Theories in medical education: towards creating a union between educational practice and research traditions. Medical Teacher 2001;33:183-187.

(46) Punch KF. Punch KF. Introduction to Social Research: Quantitative and Qualitative Approaches. Thousand Oaks, CA: Sage; 1998.

(47) Eva KW, Lingard L. What's next? A guiding question for educators engaged in educational research. . Medical Education 2008;42:752-754.

(48) Bordage G. Conceptual frameworks to illuminate and magnify. Med Educ 2009;43(4):312-319.

(49) Ball S. Politics and Policy Making in Education: explorations in policy sociology. London: Routledge; 1990.

(50) Holland D, Lachicotte W, Skinner D, Cain C. Identity and Agency in Cultural Worlds. Cambridge: Harvard University Press; 1998.

(51) Kemmis S, Wilkinson J, Edwards-Groves C, Hardy I, Grootenboer P, Bristol L. Changing practices, changing education. London: Springer; 2014.

(52) Mahon K, Kemmis S, Francisco S, Lloyd A. Introduction: Practice theory and the theory of practice architectures. In: Mahon K, Francisco S, Kemmis S, editors. Exploring Education and Professional Practice: Through the Lens of Practice Architectures Singapore: Springer; 2016. p. 1-30.

(53) Lave J, Wenger E. Situated Learning: Legitimate Peripheral Participation. Cambridge: Cambridge University Press; 1991.

(54) Steven K, Wenger E, Boshuizen H, Scherpbier A, Dornan T. How clerkship students learn from real patients in practice settings. Acad Med 2014;89(3):469-476.

(55) Renting N, Raat ANJ, Dornan T, Wenger-Trayner E, van der Wal MA, Borleffs JCC, et al. Integrated and implicit: how residents learn CanMEDS roles by participating in practice. Med Educ 2017;51(9):942-952.

(56) Engeström Y. Engeström, Y. (1999) Innovative learning in work teams: analysing cycles of knowledge creation in practice, in: Y. ENGESTRÖM et al (Eds.) Perspectives on Activity Theory, (Cambridge, Cambridge University Press), 377-406. In: Engeström Y, Miettinen R, Punamäki RL, editors. Perspectives on Activity Theory Cambridge: Cambridge University Press; 1999. p. 377-406.

(57) Engeström Y. Activity theory as a framework for analysing and redesigning work. Ergonomics 2000;43(7):960-974.

(58) Engeström Y. Learning by Expanding: an Activity-Theoretical Approach to Developmental Research. Helsinki: OrientaKonsultit; 1987.

(59) Sfard A. On two metaphors for learning and the dangers of choosing just one. Educational Research 1998;27:4-13. 
(60) Kemmis S, Grootenboer P. Situating Praxisin Practice. In: Kemmis S, Smith T, editors. Enabling Praxis: Challenges for Education Rotterdam: Sense; 2008. p. 37-62.

(61) Fenwick T, Edwards R. Performative Ontologies: Sociomaterial Approaches to Researching Adult Education and Lifelong Learning. European Journal for Research on the Education and Learning of Adults 2013;4(1):49-63.

(62) Nespor J. Knowledge in Motion: Space, Time and Curriculum in Undergraduate Physics and Management. London: Routledge; 1994.

(63) Hodges DC. Participation as dis-identification withy/in a community of practice. Mind, Culture, and Activity 1998;5(4):272-290.

(64) Gomez ML. Discourses of an aspiring teacher of color in the figured world of schooling. Teacher Education Quarterly 2014;41(1):45-62.

(65) Urrieta L, Jr. Figured Worlds and Education: An Introduction to the Special Issue. The Urban Review 2007;39(2):107-116.

(66) Rush LS, Fecho B. When figured worlds collide: Improvisation in an inquiry classroom. Teach Educ 2008;19(2):123-136.

(67) Gonsalves A, Rahm J, Carvalho A. "we could think of things that could be science": Girls' refiguring of science in an out-of-school-time club. J Res Sci Teach 2013;50(9):1068-1097.

(68) Price JF, McNeill KL. Toward a lived science curriculum in intersecting figured worlds: An exploration of individual meanings in science education. J Res Sci Teach 2013;50(5):501-529.

(69) Dornan T, Pearson E, Carson P, Helmich E, Bundy C. Emotions and identity in the figured world of becoming a doctor. Med Educ 2015;49(2):174-185.

(70) Stubbing E, Helmich E, Cleland J. Authoring the identity of learner before doctor in the figured world of medical school. Perspectives in Medical Education 2018;17(1):40-46.

(71) Hill E, Solomon Y, Dornan T, Stalmeijer R. 'You become a man in a man's world': is there discursive space for women in surgery? Med Educ 2015;49(12):1207-1218.

(72) van Lankveld T, Schoonenboom J, Kusurkar RA, Volman M, Beishuizen J, Croiset G. Integrating the teaching role into one's identity: a qualitative study of beginning undergraduate medical teachers. Adv Health Sci Educ 2017;22(3):601-622.

(73) Bennett D, Solomon Y, Bergin C, Horgan M, Dornan T. Possibility and agency in Figured Worlds: becoming a 'good doctor'. Med Educ 2017;51(3):248-257.

(74) Reines HD, Robinson L, Nitzchke S, Rizzo A. Defining service and education: the first step to developing the correct balance. Surgery (USA) 2007;142(2):303-310.

(75) Lortie D. Schoolteacher: a sociological study. Chicago: University of Chicago Press; 2002.

(76) Fecho B, Graham P, Hudson-Ross S. Appreciating the wobble: Teacher research, professional development, and figured worlds. English Education 2005;37(3):174-199. 
(77) Boaler J, Greeno JG. Identity, agency, and knowing in mathematics worlds. In: Boaler J, editor. Multiple perspectives on mathematics teaching and learning Stamford, CT: Elsevier Science; 2000. p. 171-2000.

(78) Schatzki TR. A primer on practices: Theory and research. In: Higgs J, Barnett R, Billett S, Hutchings M, Trede F, editors. Practice-Based Education: Perspectives and Strategies: Sense Publishers; 2012. p. 13-26.

(79) Schatzki TR. On organizations as they happen. Organ Stud 2006;27(12):1863-1873.

(80) Edwards-Groves C, Grootenboer P. Praxis and the theory of practice architectures: Resources for re-envisioning English education. Aust J Lang Lit 2015;2015(OCT).

(81) Wenger E. Communities of Practice: Learning, Meaning and Identity. Cambridge: Cambridge University Press; 1998.

(82) Bloch M, Lave J, Wenger E. Situated learning: Legitimate peripheral participation. In: Pea R, Brown JS, editors. Man (Vol 29) Cambridge: Cambridge University Press; 1994.

(83) Borzilla S, Aznar S, Schmitt A. A journey through communities of practice: How and why members move from the periphery to the core. (1), 25-42. European Management Journal 2011;29(1):25-42.

(84) Handley K, Sturdy A, Fincham R, Clark T. Within and beyond communities of practice: Making sense of learning through participation, identity and practice. Journal of Management Studies 2006;43(3):641-653.

(85) Ranmuthugala G, Georgiou A, Braithwaite J, Cunningham FC, Westbrook JI, Plumb JJ. (How and why are communities of practice established in the healthcare sector? A systematic review of the literature. , 11(1), 273. BMC Health Services Research 2011;11(1):273.

(86) Kitto SC, Grant RE, Peller J, Moulton C, Gallinger S. What's in a name? Tensions between formal and informal communities of practice among regional subspecialty cancer surgeons. Advances in Health Sciences Education 2018;23(1):95-113.

(87) Cleland J, Walker KG, Gale M, Nicol LG. Simulation-based education: understanding the sociocultural complexity of a surgical training 'boot camp'. Med Educ 2016;50(8):829-841.

(88) Battista A. Activity Theory and Analyzing Learning in Simulations. Simul Gaming 2015;46(2):187196.

(89) Eppich W, Cheng A. How Cultural-Historical Activity Theory can Inform Interprofessional Team Debriefings. Clin Simul Nurs 2015;11(8):383-389.

(90) Mumby DK. Theorizing resistance in organization studies: A Dialectical Approach. Manage Commun Q 2005;19(1):19-44.

(91) Mills S. Discourse. 2nd ed. London: Routledge; 2004.

(92) Kuper A, Whitehead C, Hodges BD. Looking back to move forward: using history, discourse and text in medical education research: AMEE guide no. 73. Med Teach 2013;35(1):e849-860. 
(93) Leppink J, Van Gog T, Paas F, Sweller J. Cognitive load theory: researching and planning teaching to maximise learning . In: Cleland J, Durning SJ, editors. Researching medical education. 1st ed. UK, Chicester.: Wiley-Blackwell; 2015. p. 207-218.

(94) Durning SJ, Lubarsky S, Torre D, Dory V, Holmboe E. Considering "Nonlinearity" Across the Continuum in Medical Education Assessment: Supporting Theory, Practice, and Future Research Directions. J Cont Educ Health Prof 2015;35(3):232-243.

(95) Cleland J. Exploring versus measuring: Considering the fundamental differences between qualitative and quantitative research. In: Cleland J, Durning SJ, editors. Researching Medical Education. First ed. Oxford: Wiley Blackwell; 2015. p. 3-14.

(96) Lewin K. Psychology and the process of group living. Journal of Social Psychology 1943(17):113131. 


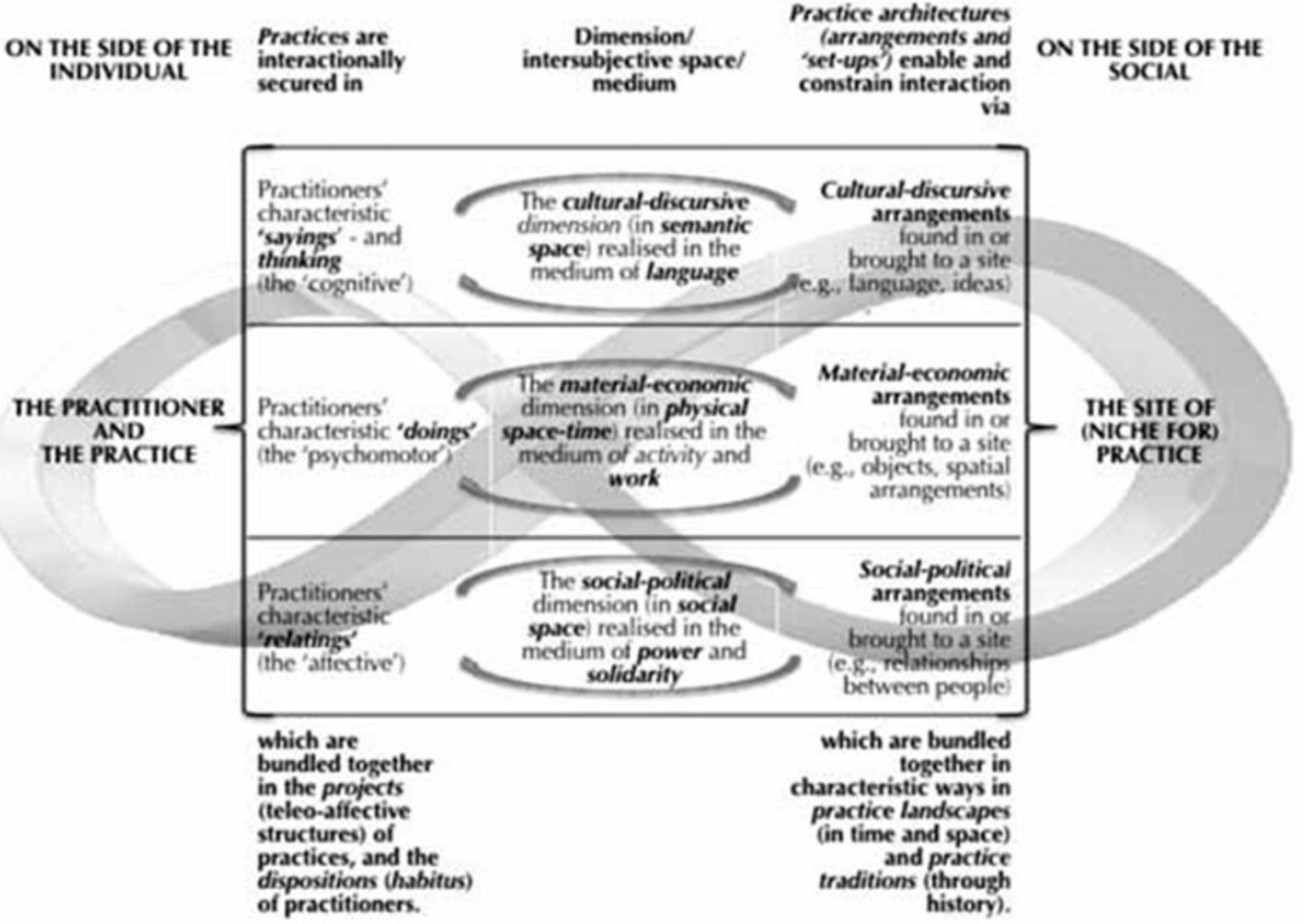

Figure 1. The theory of practice architectures (Kemmis et al., 2014) 
Figure 2: Engeström's (1999) (56) third generation activity theory model

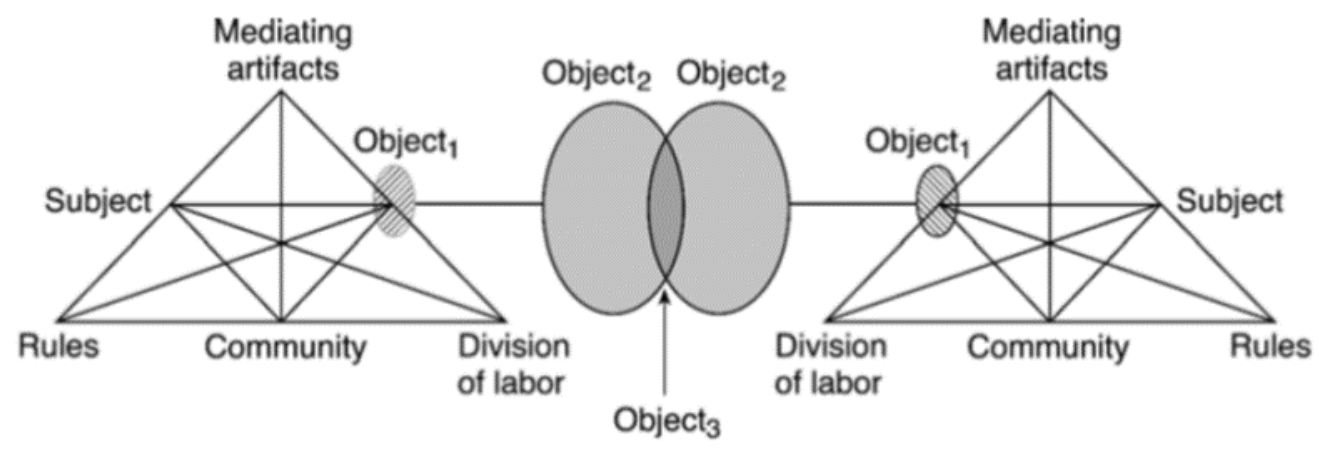


Table 1. Overview: the four theories, what they emphasize, their utility and some examples of possible research questions on the topic of serviceeducation tensions that each theory could address.

\begin{tabular}{|c|c|c|c|}
\hline Theory & Emphasis Relating to Tensions & Key principles/themes & Examples of possible research questions \\
\hline $\begin{array}{l}\text { Figured worlds } \\
(50)\end{array}$ & $\begin{array}{l}\text { The individual's response to, and } \\
\text { interpretation of, day-to-day } \\
\text { experiences and activities. }\end{array}$ & $\begin{array}{l}\text { Impact of negotiating/experiencing } \\
\text { service-training tensions on the } \\
\text { development of professional practices } \\
\text { and professional identity. }\end{array}$ & $\begin{array}{l}\text { How does a trainer's support, or perceived lack of support, } \\
\text { impact on resident professional identity development? } \\
\text { How does juggling multiple, competing demands influence } \\
\text { Consultant views of their own identity as trainers? }\end{array}$ \\
\hline $\begin{array}{l}\text { Practice } \\
\text { architectures } \\
(51,52)\end{array}$ & $\begin{array}{l}\text { Practices occur in, and are } \\
\text { enmeshed with, places. Cultural } \\
\text { and social factors are important } \\
\text { but so are material and economic } \\
\text { conditions. }\end{array}$ & $\begin{array}{l}\text { Looking beyond the individual, to also } \\
\text { include consideration of systems factors } \\
\text { that maintain or hold practices in place, } \\
\text { and which would need to be addressed } \\
\text { to enable change. }\end{array}$ & $\begin{array}{l}\text { How is medical training enabled and/or constrained by the } \\
\text { economic and/or regulatory set-up of the world in which it is } \\
\text { located? } \\
\text { What is the influence of the rota design on relationships } \\
\text { between trainees/residents and their supervisor, or the } \\
\text { wider team? (If negative, how could the rota be changed to } \\
\text { improve relationships)? }\end{array}$ \\
\hline $\begin{array}{l}\text { Situated learning } \\
(53-55)\end{array}$ & $\begin{array}{l}\text { Learning is situated within a } \\
\text { specific place and time and } \\
\text { involves interacting within a } \\
\text { community of practice (CoP). } \\
\text { Learning within this CoP entails } \\
\text { active participation that expands } \\
\text { over time. }\end{array}$ & $\begin{array}{l}\text { Looking at the interaction of the } \\
\text { individual learner and the wider group, } \\
\text { and how engaging with the wider group } \\
\text { leads to learning. }\end{array}$ & $\begin{array}{l}\text { What influence do service demands have on the } \\
\text { development and success of a CoP? } \\
\text { How do service-training tensions interact to facilitate, or } \\
\text { hinder, the journey from peripheral to full participation for } \\
\text { trainees/residents? }\end{array}$ \\
\hline $\begin{array}{l}\text { Activity theory } \\
(56-58)\end{array}$ & $\begin{array}{l}\text { Like situated learning, takes into } \\
\text { account not only the individual } \\
\text { but also their social and cultural } \\
\text { context. The system not the } \\
\text { individual is the focus. }\end{array}$ & $\begin{array}{l}\text { AT can help make explicit the history } \\
\text { and culture of groups/systems, examine } \\
\text { on the component parts of a system } \\
\text { interact, and examine how different } \\
\text { activity systems interact. }\end{array}$ & $\begin{array}{l}\text { How do the different systems involved in surgical (or any } \\
\text { specialty) training interact to inhibit or support learning? } \\
\text { Do the structures of different healthcare education } \\
\text { programmes influence how multiple groups of healthcare } \\
\text { learners interact on (e.g., maternity) wards? }\end{array}$ \\
\hline
\end{tabular}

